\title{
Seminário de Doutoramento "Imagem Medieval, Investigação e reflexão interdisciplinar"
}

\section{Maria Coutinho}

\section{(2) OpenEdition}

1 Journals

\section{Edição electrónica}

URL: http://journals.openedition.org/medievalista/237

DOI: 10.4000/medievalista.237

ISSN: 1646-740X

\section{Editora}

Instituto de Estudos Medievais - FCSH-UNL

\section{Refêrencia eletrónica}

Maria Coutinho, « Seminário de Doutoramento "Imagem Medieval, Investigação e reflexão interdisciplinar" », Medievalista [Online], 10 | 2011, posto online no dia 01 julho 2011, consultado o 15 setembro 2020. URL : http://journals.openedition.org/medievalista/237

Mediavalista está Internacional. 
Título: Seminário de Doutoramento "Imagem Medieval, Investigação e reflexão interdisciplinar"

Autor(es): Maria Coutinho

Enquadramento Institucional: Membro do Instituto de Estudos Medievais, FCSH-UNL; Membro do IHA, FCSH-UNL

Contacto: maria1coutinho@fesh.unl.pt

Fonte: Medievalista [Em linha]. №10, (Julho 2011). Direc. José Mattoso. Lisboa: IEM. Disponível em: http://www2.fcsh.unl.pt/iem/medievalista/

ISSN: 1646-740X

\section{Seminário de Doutoramento "Imagem Medieval, Investigação e reflexão interdisciplinar"}

Maria Coutinho 


\section{IMAGEM MEDIEVAL}

Investigaçằo e reflexão interdisciplinur

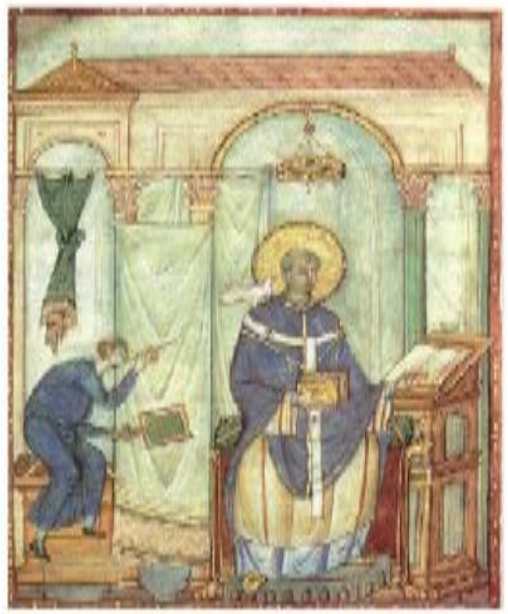

$2010-2011$

O Seminário de de Doutoramento "Imagem Medieval, Investigação e reflexão interdisciplinar" decorreu no $1^{\mathrm{o}}$ semestre do ano lectivo de 2010-2011 numa organização conjunta entre o IEM (Instituto de Estudos Medievais), o CESEM (Centro de Estudos de Sociologia e Estética Musical), IHA (Instituto de História da Arte e o CEIL (Centro de Estudos do Imaginário Literário), e com coordenação científica de Adelaide Miranda, Bernardo Vasconcelos e Sousa, Manuel Pedro Ferreira e Rosário Paixão.

Visando uma abordagem interdisciplinar de questões relacionadas com a Imagem Medieval, o Seminário promoveu cerca de 8 sessões com conferências de reputados especialistas nacionais e estrangeiros, que se destinaram não só a estudantes inscritos em Doutoramento na FCSH, como a outros participantes.

A iniciativa inseriu-se num projeto mais vasto de articulação de diversos campos de investigação que, a par das investigações transdisciplinares, procurou fomentar o debate sobre aspectos teóricos e metodológicos dos estudos medievais. Interesse e preocupação desde logo traduzidos nos objectivos do Seminário:

- $\quad$ Integrar o doutorando num ambiente interdisciplinar de investigação.

- $\quad$ Oferecer a possibilidade de contacto com as mais recentes metodologias e abordagens às diferentes áreas compreendidas pelo curso. 
- Possibilitar uma visão nacional e internacional do estado da questão das temáticas desenvolvidas.

- Aprofundar o conhecimento e a compreensão crítica dos referenciais teóricometodológicos da imagem medieval e da sua aplicação em contextos de investigação diversificados e interdisciplinares.

Facilitar os contactos internacionais para uma visão mais ampla dos problemas levantados ao longo da investigação.

- Dar particular relevo aos contextos hispânicos, mediterrânico e atlântico nos quais se afirmou a estrutura e sociedade medieval portuguesa.

Desde modo, e para tal, foi promovida uma sessão de Literatura com Philippe Walter e Irene Freire Nunes, duas de História da Arte com José Custódio da Silva e Etelvina Fernandez, de Musicologia com Maria Cármen Gómez i Muntané e Manuel Pedro Ferreira, de História com Adeline Rucquoi e Bernardo Vasconcelos e Sousa, e ainda de

práticas metodológicas sobre métodos de pesquisa, constituição de corpus e levantamento de questões, a partir de uma comunicação de José Mattoso.

Ao longo das sessões debateu-se a semiologia complexa da imagem, a sua definição, suporte que a sustenta (verbal, visual, mental, pictural), processos de simbolização, convergência de motivos que formam imagem e constituem um imaginário, ou ainda $o$ modo como a transformação orgânica e intelectual do Homem altera a sua concepção de Imagem, no domínio artístico, musical, literário, ou em fontes documentais.

\section{COMO CITAR ESTE ARTIGO}

\section{Referência electrónica:}

COUTINHO, Maria - Seminário de Doutoramento "Imagem Medieval, Investigação e reflexão interdisciplinar". Medievalista [Em linha]. №10, (Julho de 2011). [Consultado dd.mm.aaaa]. Disponível em http://www2.fcsh.unl.pt/iem/medievalista/MEDIEVALISTA10lcoutinho1011.html. ISSN 1646-740X. 
Seminário de Doutoramento "Imagem Medieval, Investigação e reflexão interdisciplinar" • Maria Coutinho

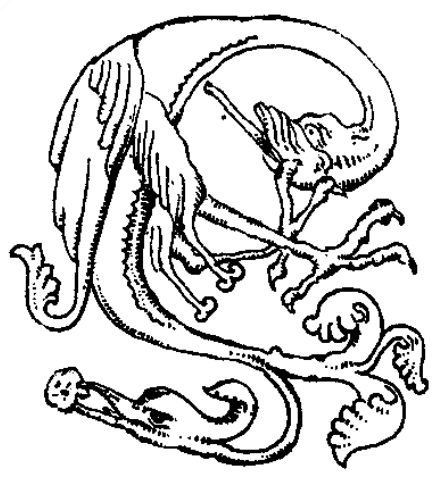

Medievalísta online $\mathrm{N}^{\circ} 10 \mid$ Julho - Dezembro 2011 @ IEM - Instituto de Estudos Medievais 4 www2.fcsh.unl.pt/iem/medievalista 